\title{
Resveratrol Inhibits Angiogenic Response of Cultured Endothelial F-2 Cells to Vascular Endothelial Growth Factor, but Not to Basic Fibroblast Growth Factor
}

\author{
Tomomi Uchiyama, ${ }^{a}$ Ken-ichi Toda, ${ }^{b}$ and Satoru TaKahashi ${ }^{*, a}$ \\ ${ }^{a}$ First Department of Biochemistry, School of Pharmaceutical Sciences, Kyushu University of Health and Welfare; 1714-1 \\ Yoshino, Nobeoka, Miyazaki 882-0072, Japan: and ${ }^{b}$ Department of Dermatology, Kitano Hospital, Tazuke Kofukai \\ Medical Research Institute; 2-4-20 Ohgimachi, Kita-ku, Osaka 530-8480, Japan. \\ Received January 21, 2010; accepted April 2, 2010; published online April 6, 2010
}

\begin{abstract}
Resveratrol, a natural polyphenol in grapes, is known to prevent the cardiovascular diseases and to exert the antiangiogenic effect in in vivo models with vascular endothelial growth factor (VEGF) or basic fibroblast growth factor (bFGF). We examined the effect of resveratrol on tubule formation of cultured endothelial F-2 cells. In collagen gel matrix, F-2 cells formed an extended network of tubular structures in response to VEGF or bFGF. Resveratrol dose-dependently prevented the VEGF-induced tubule formation, but failed to inhibit the angiogenic response to bFGF. We next examined whether the inhibition of nitric oxide (NO) production is linked to the antiangiogenic effect of resveratrol on VEGF-stimulated F-2 cells, because NO plays a crucial role in VEGFinduced tubular network formation. NO production was increased by VEGF, but not by bFGF, and resveratrol inhibited VEGF-stimulated NO production. $N^{\mathrm{G}}$-nitro-L-arginine methyl ester (L-NAME) potently inhibited NO production under all conditions, including VEGF stimulation, and abrogated VEGF-induced tubule formation. However, L-NAME did not inhibit bFGF-induced tubule formation. To investigate the bFGF-induced in vivo antiangiogenic effect of resveratrol, we examined the effect of resveratrol on prostaglandin $\mathrm{E}_{2}\left(\mathrm{PGE}_{2}\right)$ production and cyclooxygenase (COX) expression in NRK-F fibroblasts. COX-2 and its derived $\mathrm{PGE}_{2}$ are important factors for bFGF-induced in vivo angiogenesis. Resveratrol dose-dependently prevented both COX-2 induction and $\mathrm{PGE}_{2}$ production in bFGF-stimulated fibroblasts. These results suggest that resveratrol exerts the inhibitory effects on VEGF- and bFGF-induced angiogenesis through different mechanisms including inhibition of NO production in VEGF-stimulated endothelial cells and inhibition of COX-2 induction in bFGF-stimulated fibroblasts.
\end{abstract}

Key words resveratrol; endothelial cell; angiogenesis; vascular endothelial growth factor; basic fibroblast growth factor

Resveratrol, a polyphenolic compound found abundantly in grapes and red wines, is known to have cardiovascular protective effects that lower the risks of coronary heart disease and atherosclerosis. ${ }^{1,2)}$ Resveratrol has also been found to inhibit the formation and development of neoplastic lesions in animal models. ${ }^{3-9)}$ Resveratrol exerts various biochemical effects, including antioxidation, ${ }^{3,10}$ induction of apopto$\mathrm{sis}^{4,6-8)}$ and inhibition of angiogenesis, ${ }^{4,5,7,8,11)}$ which are thought to contribute to its antitumor activity.

Angiogenesis is a process by which new blood vessels are formed from preexisting microcapillaries, and this process is essential for the growth and persistence of tumors and their metastases. ${ }^{12,13)}$ Angiogenesis is induced in response to various angiogenic factors such as vascular endothelial growth factor (VEGF) and basic fibroblast growth factor (bFGF). These growth factors stimulate the endothelial migration, proliferation and tubule formation during angiogenesis. It was reported that resveratrol inhibits both VEGF- and FGF-2 (bFGF)-induced angiogenic responses in a mouse corneal micropocket model ${ }^{5)}$ and that resveratrol exerts significant inhibition of FGF-2-induced angiogenesis in a chick chorioallantoic membrane model. ${ }^{7)}$ Lin et al. ${ }^{11)}$ reported that resveratrol prevents VEGF-induced tubular network formation of cultured endothelial cells. However, it remains unknown whether bFGF-induced tubular network formation of endothelial cells is also inhibited by resveratrol. In the present study, we investigated the antiangiogenic effect of resveratrol in cultured endothelial F-2 cells stimulated with VEGF or bFGF. Resveratrol directly inhibited angiogenic response of F-2 cells to VEGF, but not to bFGF. We subsequently exam- ined the antiangiogenic mechanisms of resveratrol; (1) the inhibitory effect specific for VEGF in endothelial cells and (2) the effect on bFGF-stimulated prostaglandin $\mathrm{E}_{2}\left(\mathrm{PGE}_{2}\right)$ production in fibroblasts.

Endothelial cells constitutively express endothelial nitric oxide synthase (eNOS), which is responsible for nitric oxide (NO) generation. NO plays a crucial role in regulating endothelial functions, ${ }^{14)}$ and is important for tubular network formation of endothelial cells. ${ }^{15-17)}$ We recently reported that resveratrol at low concentrations $(<20 \mu \mathrm{M})$ decreases NO production in VEGF-stimulated F-2 cells. ${ }^{18)}$ Cyclooxygenase-2 (COX-2) also plays an important role in angiogenesis. COX-2 is induced by bFGF in fibroblasts of the neovascular tissues, and COX-2-derived $\mathrm{PGE}_{2}$ is required for bFGFinduced angiogenesis. ${ }^{19-21)}$ Therefore, we evaluated whether the inhibition of NO production is involved in the direct effect of resveratrol on only VEGF-stimulated endothelial cells, and whether resveratrol impairs COX-2 induction in bFGF-stimulated fibroblasts as the indirect antiangiogenic effect.

\section{MATERIALS AND METHODS}

Materials The reagents used in this study and their sources are as follows: resveratrol, $N^{\mathrm{G}}$-nitro-L-arginine methyl ester (L-NAME), indomethacin and NS-398 (SigmaAldrich; St. Louis, MO, U.S.A.); recombinant human vascular endothelial growth factor (VEGF) and human basic fibroblast growth factor (bFGF) (PeproTech; Rocky Hill, NJ, U.S.A.); cell culture media and supplies (Invitrogen; Carls- 
bad, CA, U.S.A.); anti-COX-1 and anti-COX-2 antibodies, and $\mathrm{PGE}_{2}$ EIA kits (Cayman Chemicals; Ann Arbor, MI, U.S.A.); secondary antibody linked to peroxidase, and Phototope-HRP Western Blot detection system (Cell Signaling; Beverly, MA, U.S.A.); Immobilon-P membrane (Millipore; Bedford, MA, U.S.A.); WST-8 (Dojin Laboratories, Kumamoto, Japan). Resveratrol and COX inhibitors were dissolved in dimethyl sulfoxide, followed by dilution with culture medium. The final concentration of the solvent in culture wells was less than $0.5 \%$. All other chemicals were of reagent grade.

Cell Culture F-2 cells, a mouse vascular endothelial cell line, proliferate and migrate in response to VEGF and bFGF. ${ }^{18,22)}$ NRK-F fibroblasts were kindly supplied from Dr. Kazuhisa Nakayama (Faculty of Pharmaceutical Sciences, Kyoto University). F-2 cells and NRK-F cells were maintained in Dulbecco's modified Eagle's medium (DMEM) supplemented with $10 \%$ fetal bovine serum (FBS), $100 \mathrm{U} / \mathrm{ml}$ penicillin, and $100 \mu \mathrm{g} / \mathrm{ml}$ streptomycin at $37^{\circ} \mathrm{C}$ in $5 \% \mathrm{CO}_{2}$ and $95 \%$ air.

Tubular Network Formation Assay Tubular network formation of F-2 cells was assessed in collagen gel matrix. Collagen was extracted from the tail tendon of male Wistar rats (Nihon SLC, Hamamatsu, Japan) using 0.1\% acetic acid. Seven volumes of $0.5 \mathrm{mg} / \mathrm{ml}$ collagen solution were mixed with 2 volumes of 5 -fold concentrated $\mathrm{NaHCO}_{3}$-free DMEM and 1 volume of reconstitution buffer (4.77 $\mathrm{g} \mathrm{N}$-(2-hydroxyethyl)piperazine- $N$ '-2-ethanesulfonic acid (HEPES) and $2.2 \mathrm{~g} \mathrm{NaHCO}_{3}$ in $100 \mathrm{ml}$ of $50 \mathrm{~mm} \mathrm{NaOH}$ ), after which the solution was kept on ice. The mixture $(400 \mu \mathrm{l})$ was added into each well of 24 -well plates and incubated at $37^{\circ} \mathrm{C}$ for $30 \mathrm{~min}$ to allow gel formation (bottom layer). After the gel solidified, F-2 cells $\left(4 \times 10^{4}\right.$ cells $/ 0.8 \mathrm{ml}$ of $0.1 \% \mathrm{FBS} /$ DMEM) were seeded onto the bottom layer and incubated at $37^{\circ} \mathrm{C}$ for $6 \mathrm{~h}$ to adhere to the collagen gels. Subsequently, the remaining culture medium was removed, and $260 \mu \mathrm{l}$ of the collagen mixture was added onto the bottom layer, which was followed by solidification at $37^{\circ} \mathrm{C}$ for $30 \mathrm{~min}$ (top layer). After adding $0.1 \%$ FBS/DMEM $(400 \mu \mathrm{l})$ containing vehicle or the otherwise indicated agents onto the top layer, the cells were incubated at $37^{\circ} \mathrm{C}$ in $5 \% \mathrm{CO}_{2}$ and $95 \%$ air for $24 \mathrm{~h}$. The agents diffused into the gel matrix within $1 \mathrm{~h}$, and their concentrations were diluted by 2 -fold. Tube-like network formation was observed using a phase-contrast microscope (magnification $\times 100$ ) equipped with a digital camera. Four randomly chosen fields were photographed, and the total tubule length was measured.

Cell Viability Assay The viability of F-2 cells was assessed by the colorimetric method using water soluble tetrazolium (WST)-8 according to the manufacturer's instruction. F-2 cells were seeded in 96-well plates and then incubated in $0.1 \% \mathrm{FBS} / \mathrm{DMEM}$ containing VEGF and/or resveratrol for $24 \mathrm{~h}$. Two hours after WST-8 solution was added to the wells, the absorbance was measured at $450 \mathrm{~nm}$.

NO Production Assay F-2 cells were seeded in 12-well plates and were allowed to grow to semi-confluence. The cells were incubated overnight in $0.1 \% \mathrm{FBS} / \mathrm{DMEM}$ and then stimulated with VEGF or bFGF in the presence or absence of resveratrol for $30 \mathrm{~min}$. In the case of addition of an eNOS inhibitor, the cells had been pretreated with $1 \mathrm{mM} \mathrm{L}-$ NAME for $10 \mathrm{~min}$ before growth factor stimulation. NO was determined as nitrite by colorimetry after the Griess reaction, as we reported previously. ${ }^{18)} \mathrm{NO}$ released into the medium was completely oxidized to nitrite when left overnight at $4{ }^{\circ} \mathrm{C}$. In a preliminary experiment performed in this study, the amount of nitrite was confirmed to be stable under this condition. The amount of nitrite was measured using a $\mathrm{NO}_{x}$ analyzer (ENO-200; EICOM, Kyoto, Japan).

PGE 2 Production Assay Cells were seeded in 12-well plates and were allowed to grow to semi-confluence. The cells were incubated overnight in $0.1 \%$ FBS/DMEM and then stimulated with VEGF or bFGF in the presence or absence of resveratrol for $20 \mathrm{~h}$. In the case of addition of COX inhibitors, the cells had been pretreated with $25 \mu \mathrm{M}$ indomethacin or NS-398 for $10 \mathrm{~min}$ before growth factor stimulation. $\mathrm{PGE}_{2}$ production was determined using $\mathrm{PGE}_{2}$ EIA kit according to the manufacturer's instruction.

Immunoblot of COX Proteins NRK-F cells were lysed in buffer A consisting of $20 \mathrm{~mm}$ Tris- $\mathrm{HCl}(\mathrm{pH} 7.5), 1 \mathrm{~mm}$ ethylenediaminetetraacetic acid (EDTA), $100 \mathrm{~mm} \mathrm{NaCl}$, $10 \mathrm{~mm}$ sodium orthovanadate, $10 \mathrm{~mm}$ sodium fluoride, $10 \mathrm{~mm}$ $\beta$-glycerophosphate, $1 \%$ Triton $\mathrm{X}-100,0.5 \%$ sodium deoxycholate, and the protease inhibitor mixture. The lysates were placed on ice for $10 \mathrm{~min}$ and were centrifuged at $10000 \boldsymbol{g}$ for $10 \mathrm{~min}$ at $4{ }^{\circ} \mathrm{C}$. The resulting supernatants were subjected to sodium dodecylsulfate-polyacrylamide gel electrophoresis (SDS-PAGE) and then blotted onto Immobilon-P membranes. The blots were incubated overnight with the primary antibody at $4{ }^{\circ} \mathrm{C}$ and then probed with the secondary antibody linked to peroxidase. Immunoreactive proteins were visualized using an enhanced chemiluminescence kit. Anti-COX-1 and anti-COX-2 antibodies reacted the respective $70 \mathrm{kDa}-$ proteins, whose mobility on SDS-PAGE were identical to those of the standard COX proteins.

Statistical Analysis Data are expressed as means \pm S.E. Statistical differences were evaluated by Student's $t$-test or one-way ANOVA followed by Dunnett's multiple comparison test. Statistical significance was considered when $p<0.05$.

\section{RESULTS}

F-2 cells were subjected to tubular network formation assay in collagen gel matrix (Fig. 1). Under the control condition $(0.1 \%$ FBS alone), the tube-like structures were all short and did not develop into a network. F-2 cells formed an extended network of tubular structures in response to VEGF
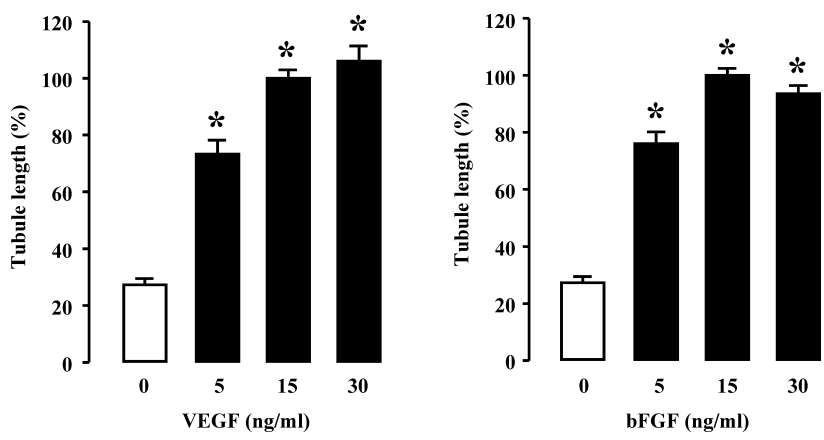

Fig. 1. Tubular Network Formation of F-2 Cells

The cells were incubated with vehicle, VEGF or bFGF for $24 \mathrm{~h}$. The total tubule length was measured and is expressed as a percentage of the value in the group stimulated with $15 \mathrm{ng} / \mathrm{ml}$ VEGF or bFGF. Data are expressed as mean \pm S.E. for six experiments. * Significantly different from the vehicle-treated group. 

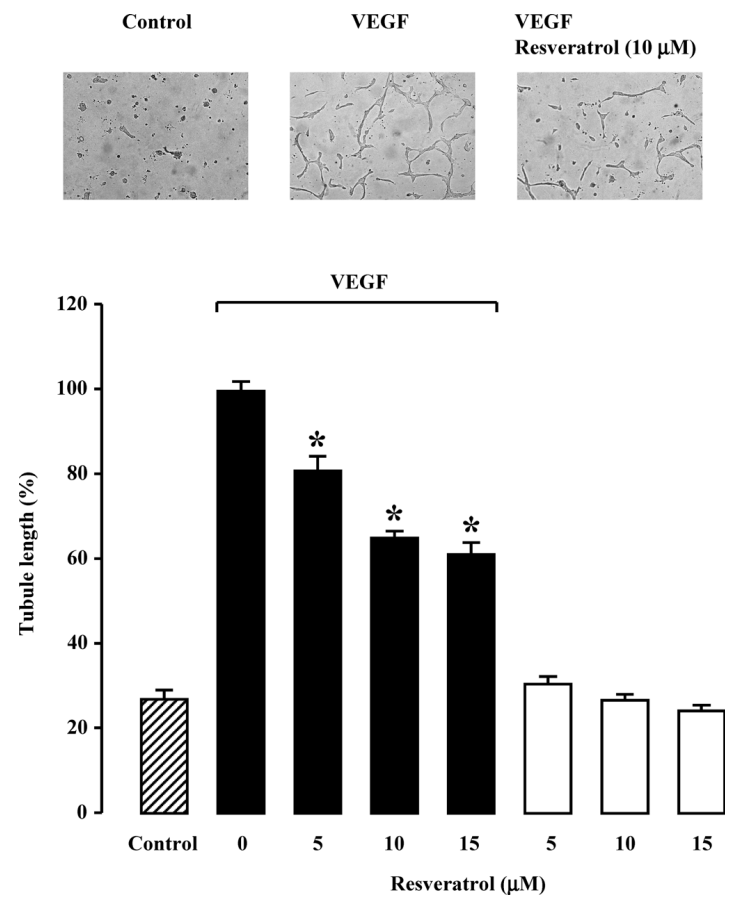

Fig. 2. Effect of Resveratrol on VEGF-Induced Tubule Formation of F-2 Cells

The cells were incubated with resveratrol in the presence or absence of $15 \mathrm{ng} / \mathrm{m}$ VEGF for $24 \mathrm{~h}$. The total tubule length was measured and is expressed as a percentage of the value in the VEGF-stimulated group. Data are expressed as mean \pm S.E. for six experiments. * Significantly different from the cells treated with VEGF alone. Typical results are shown in upper photographs (magnification: $\times 100$ ).

and bFGF in $24 \mathrm{~h}$ (see Figs. 2, 3). VEGF promoted tubular network formation in a dose-dependent manner. Similarly, bFGF-induced tubule formation was dose-dependent. A significant increase was observed in the total tubule length beginning at a growth factor concentration of $5 \mathrm{ng} / \mathrm{ml} \mathrm{com-}$ pared with the control and the effects of VEGF and bFGF reached a maximum at $15 \mathrm{ng} / \mathrm{ml}$. The maximal effects of VEGF and bFGF on the total tubule length were equivalent, although VEGF-forming tubule branch points appeared more than bFGF-forming ones. The total tubule length was $5193 \pm 623 \mu \mathrm{m} /$ field at $15 \mathrm{ng} / \mathrm{ml}$ of VEGF and $5027 \pm 513$ $\mu \mathrm{m} /$ field at $15 \mathrm{ng} / \mathrm{ml}$ of bFGF. Therefore, the concentration of $15 \mathrm{ng} / \mathrm{ml}$ was chosen for both VEGF and bFGF in the following experiments.

The effects of resveratrol on VEGF- and bFGF-induced tubular network formation of F-2 cells were examined. Resveratrol dose-dependently and significantly prevented tubule formation in response to VEGF (Fig. 2). The effect of resveratrol almost peaked at a concentration of $10 \mu \mathrm{M}$. The inhibition was $47.6 \%$ at $10 \mu \mathrm{m}$ and $52.4 \%$ at $15 \mu \mathrm{M}$. In contrast, resveratrol had no effect on bFGF-induced tubular network formation (Fig. 3). Resveratrol did not induce tubular network formation in the absence of VEGF or bFGF.

Cell viability was determined after F-2 cells were incubated with resveratrol in the presence of VEGF or bFGF for $24 \mathrm{~h}$ (Fig. 4). Resveratrol concentrations up to $20 \mu \mathrm{M}$ did not cause a substantial loss of viability. The viability was significantly reduced at a concentration of $30 \mu \mathrm{M}$. In addition, the number of F-2 cells increased $72 \mathrm{~h}$ after stimulation with VEGF or bFGF, but did not change within $48 \mathrm{~h}$, determined by direct counting under microscopic observation (data not
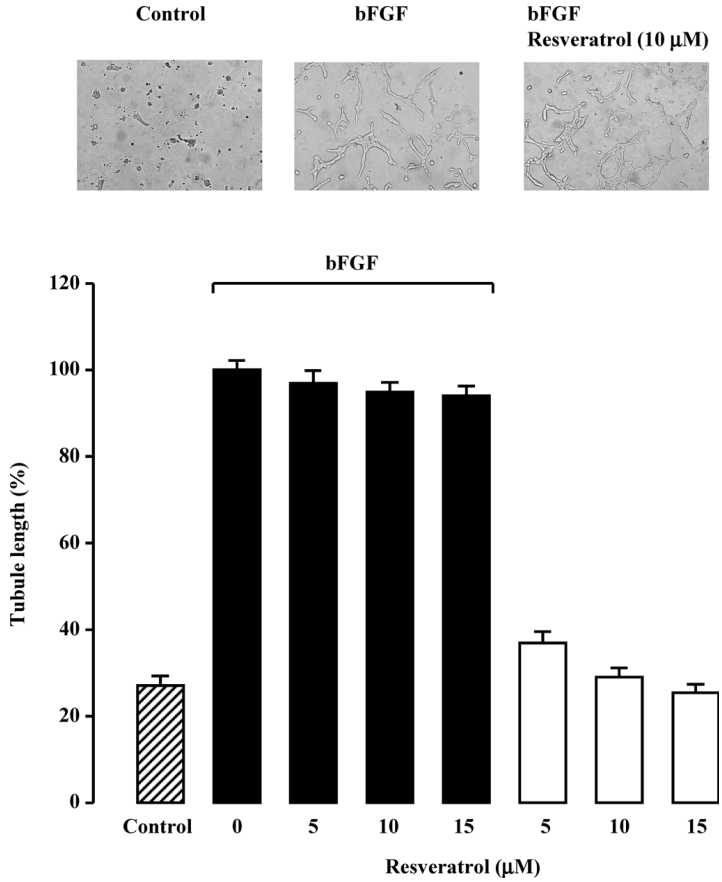

Fig. 3. Effect of Resveratrol on the bFGF-Induced Tubule Formation of F2 Cells

The cells were incubated with resveratrol in the presence or absence of $15 \mathrm{ng} / \mathrm{ml}$ bFGF for $24 \mathrm{~h}$. The total tubule length was measured and is expressed as a percentage of the value in the bFGF-stimulated group. Data are expressed as mean \pm S.E. for six experiments. $*$ Significantly different from the cells treated with bFGF alone. Typical results are shown in upper photographs (magnification: $\times 100$ ).
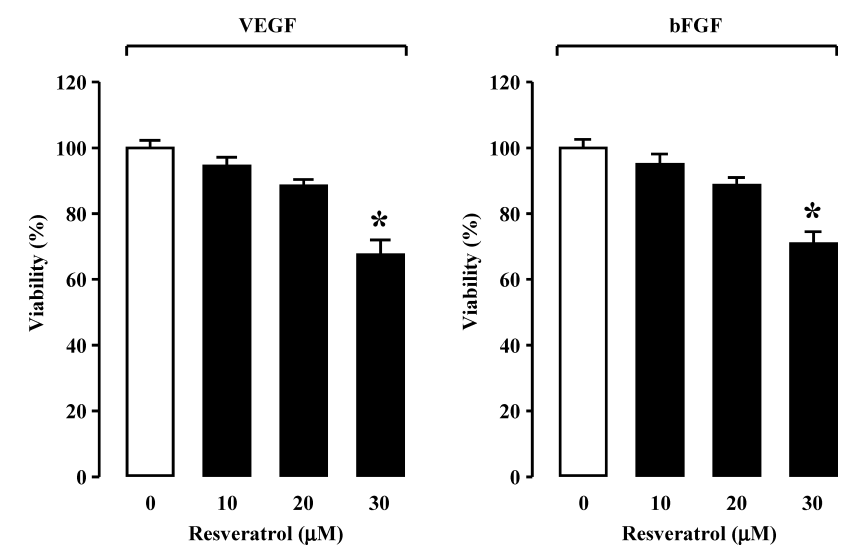

Fig. 4. Effect of Resveratrol on the Viability of F-2 Cells

The cells were incubated with resveratrol in the presence of $15 \mathrm{ng} / \mathrm{ml}$ VEGF or bFGF for $24 \mathrm{~h}$. Viability was determined by WST- 8 assay and is expressed as a percentage of the value in the vehicle-treated group. Data are expressed as mean \pm S.E. for six experiments. * Significantly different from the vehicle-treated group.

shown).

We next examined the effect of resveratrol on NO production, which plays an important role in angiogenesis. As shown in Fig. 5, VEGF enhanced NO production by 3.5 -fold, but bFGF failed to increase NO production in F-2 cells. LNAME (an NO synthase inhibitor) potently inhibited NO production under all conditions. L-NAME at a concentration of $1 \mathrm{~mm}$ reduced VEGF-stimulated NO production below the basalline in the control cells. On the other hand, resveratrol significantly inhibited VEGF-induced increase in NO production, but had no effect on either its basal production or the production in the presence of bFGF. An inhibition of 


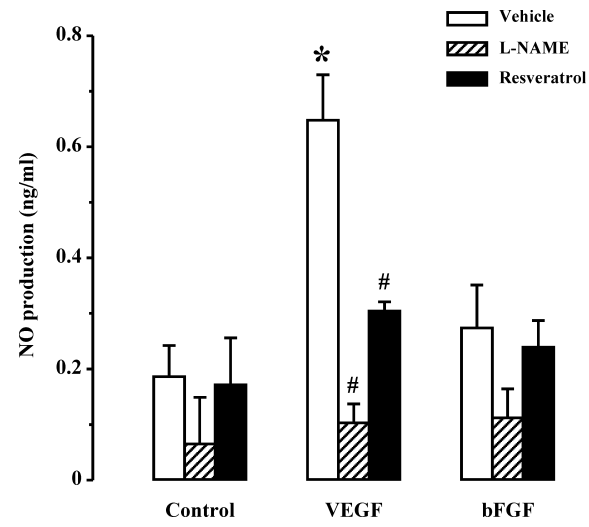

Fig. 5. Effect of Resveratrol on NO Production in F-2 Cells

The cells were incubated with vehicle, $10 \mu \mathrm{M}$ resveratrol or $1 \mathrm{~mm}$ L-NAME in the presence or absence of $20 \mathrm{ng} / \mathrm{ml}$ VEGF or bFGF for $30 \mathrm{~min}$. The amount of NO released into the medium was determined. Data are expressed as mean \pm S.E. for six experiments. *,\# Significantly different from the corresponding control and the vehicletreated cells, respectively.
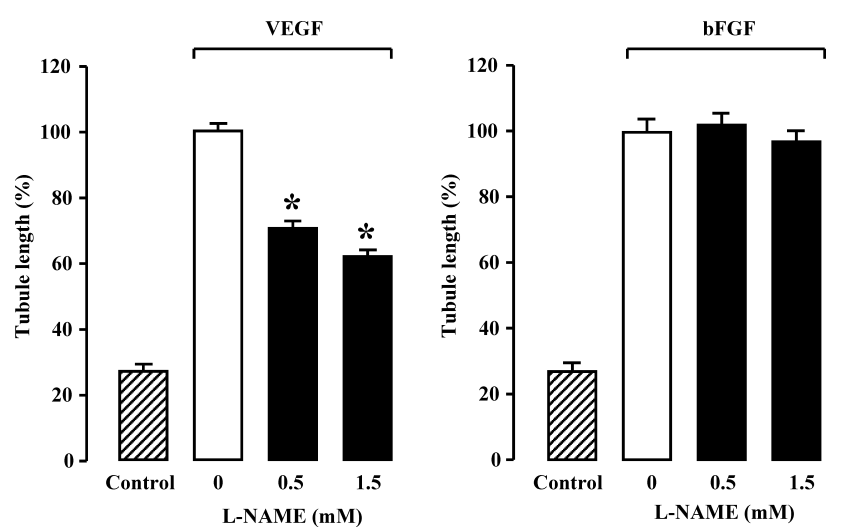

Fig. 6. Effect of L-NAME on the VEGF- and bFGF-Induced Tubule Formation of F-2 Cells

The cells were incubated with L-NAME in the presence of $15 \mathrm{ng} / \mathrm{ml}$ VEGF or bFGF for $24 \mathrm{~h}$. The total tubule length was measured and is expressed as a percentage of the value in the VEGF- or bFGF-stimulated group. Data are expressed as mean \pm S.E. for six experiments. * Significantly different from the cells treated with VEGF alone.

$72.4 \%$ in the VEGF-stimulated NO production was achieved with $10 \mu \mathrm{M}$ resveratrol.

To confirm that the inhibition of increased NO production impairs tubular network formation of F-2 cells, we examined the effect of L-NAME on in vitro angiogenesis (Fig. 6). LNAME inhibited the angiogenic response of F-2 cells to VEGF, but had no effect on bFGF-induced tubule formation. L-NAME at concentrations of $0.5 \mathrm{~mm}$ and $1.5 \mathrm{~mm}$ significantly prevented VEGF-induced tubular network formation by $38.8 \%$ and $51.0 \%$, respectively.

Previous studies demonstrate that resveratrol abrogates bFGF-induced angiogenesis in in vivo models, ${ }^{5,7)}$ whereas the polyphenol failed to inhibit the angiogenic response of cultured endothelial cells to bFGF in this study. These results suggest that resveratrol might impair the function of nonendothelial cells supporting angiogenesis, thereby indirectly inhibiting endothelial tubule formation in vivo. We therefore examined the effect of resveratrol on $\mathrm{PGE}_{2}$ production and COX-2 expression in fibroblasts (Fig. 7). When NRK-F fibroblasts were incubated with bFGF for $20 \mathrm{~h}, \mathrm{PGE}_{2}$ production significantly increased by 3.2 -fold, compared with the basal level (vehicle-treated). The cells did not respond to

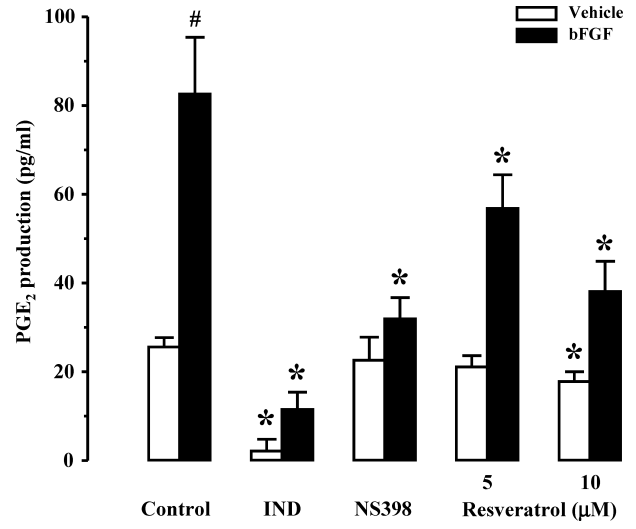

Fig. 7. Effect of Resveratrol on $\mathrm{PGE}_{2}$ Production in NRK-F Cells

The cells were incubated with vehicle, $25 \mu \mathrm{M}$ indomethacin (IND), $25 \mu \mathrm{M}$ NS-398 or resveratrol in the presence of $20 \mathrm{ng} / \mathrm{ml} \mathrm{bFGF}$ for $20 \mathrm{~h}$. The amount of $\mathrm{PGE}_{2}$ released into the medium was determined. Data are expressed as mean \pm S.E. for six experiments. $*, \#$ Significantly different from the corresponding control and the vehicle-treated cells, respectively.

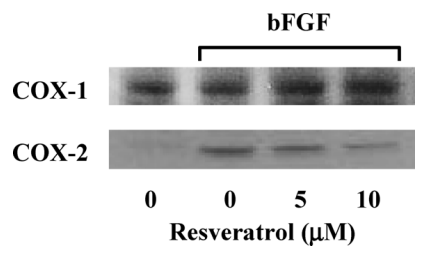

Fig. 8. Effect of Resveratrol on Expression of COX Proteins in NRK-F Cells

The cells were incubated with vehicle, or resveratrol in the presence of $20 \mathrm{ng} / \mathrm{ml}$ bFGF for $20 \mathrm{~h}$. Expression of COX-1 and COX-2 proteins was examined by immunoblotting. Data are representative of three experiments.

VEGF (data not shown). In addition, bFGF slightly promoted $\mathrm{PGE}_{2}$ production in F-2 cells $(22.4 \pm 7.9 \%$ above the basal level), but this effect was not significant. The bFGF-induced increase in $\mathrm{PGE}_{2}$ production in NRK-F cells was potently suppressed by indomethacin (a nonspecific COX inhibitor) as well as NS-398 (a COX-2-specific inhibitor). Resveratrol also inhibited the increased $\mathrm{PGE}_{2}$ production in a dosedependent manner; the inhibition was $45.3 \%$ at $5 \mu \mathrm{M}$ and $78.1 \%$ at $10 \mu \mathrm{M}$. At $10 \mu \mathrm{M}$, resveratrol significantly reduced the basal production by $30.5 \%$.

Immunoblot analysis revealed that COX-2 protein was not detected without bFGF, but induced by bFGF in NRK-F cells (Fig. 8). COX-2 expression was not induced by $10 \mu \mathrm{M}$ resveratrol alone (data not shown), but resveratrol dose-dependently inhibited bFGF-induced COX-2 expression. In contrast, COX-1 protein was expressed under the basal condition, but the level was not altered by bFGF. Resveratrol had no effect on COX-1 expression in bFGF-stimulated fibroblasts.

\section{DISCUSSION}

Resveratrol, a natural polyphenol in grapes, is known to prevent the cardiovascular diseases ${ }^{1,2)}$ and is also expected as antitumor agent. ${ }^{23)}$ Several studies showed that resveratrol suppresses tumor progression in animal models. ${ }^{3-9)}$ The inhibition of angiogenesis might contribute to the antitumor activity of resveratrol, because tumor growth requires neovascularization by which oxygens and nutrients are supplied to the proliferating cells. Resveratrol exerts a direct effect on 
human umbilical vein endothelial cells by inhibiting the VEGF-induced tubule formation. ${ }^{11)}$ In the present study, we confirmed this inhibitory effect of resveratrol in mouse endothelial F-2 cells. Resveratrol concentrations ranging from $5 \mu \mathrm{M}$ significantly abrogated tubular network formation in response to VEGF without affecting cell viability. Several investigators including us reported that resveratrol has no effect on the autophosphorylation of VEGF receptors in endothelial cells. ${ }^{11,18)}$ These observations rule out that resveratrol-induced reductions in cell viability and the functions of VEGF receptors result in the inhibition of endothelial tubule formation. The direct antiangiogenic effect on VEGF-stimulated endothelial cells seems to be more important for antitumor activity than apoptosis-inducing effect, because higher concentrations $(>20 \mu \mathrm{M})$ of resveratrol are necessary for efficient induction of tumor cell apoptosis. ${ }^{4,6,24)}$

The present study revealed that the inhibition of NO production by resveratrol might be involved in the prevention of the VEGF-induced tubule formation. Our proposed mechanism can account for the difference in the effect of resveratrol on the in vitro angiogenesis of F-2 cells. VEGF promotes the tubular network formation of endothelial cells where an increase in NO production is critical. ${ }^{15-17)}$ In contrast, bFGF does not stimulate NO production, and bFGF-induced tubule formation is NO-independent. ${ }^{16,17,25)}$ In fact, we showed that resveratrol significantly reduced NO production in VEGFstimulated F-2 cells, and that L-NAME inhibited the angiogenic response to VEGF but not to bFGF. In addition, we recently found that resveratrol at a concentration less than $20 \mu \mathrm{M}$ suppresses the phosphorylation of endothelial NO synthase at Ser-1177 in response to VEGF, resulting in decreased NO production. ${ }^{18)}$ NO plays a crucial role in the migration and proliferation of endothelial cells in response to VEGF. ${ }^{15-17)}$ F-2 cells formed tubular structures in collagen gel matrix, but did not proliferate within $24 \mathrm{~h}$ after VEGF stimulation, indicating that migration, morphological changes, and cell-to-cell contact are key factors for the in vitro angiogenesis of endothelial cells. The same observation was reported by Kubota et al. ${ }^{26)}$ Taken together, resveratrol is speculated to inhibit the NO-dependent migration and cellto-cell contact of VEGF-stimulated endothelial cells.

Wallerath et $a .^{27}$ ) reported that resveratrol causes an increase in eNOS protein content and NO production in endothelial EA.hy 926 cells. However, both quite high concentrations ( $c a .100 \mu \mathrm{M})$ of resveratrol and long-term exposure $(72 \mathrm{~h})$ are required for eNOS induction. Scifo et al. ${ }^{28)}$ and $\mathrm{we}^{18)}$ reported that resveratrol at high concentrations serves as an inducer of necrosis and apoptosis, but the cytotoxicity was not examined in the study of Wallerath et al. The present study also shows that resveratrol reduces the viability of F-2 cells even at $30 \mu \mathrm{M}$. The level of eNOS protein was not altered by $10 \mu \mathrm{M}$ resveratrol for $24 \mathrm{~h}$ (data not shown). It remains unclear whether resveratrol increases eNOS expression without loss of cell viability.

Although the decrease in NO production by resveratrol was much smaller than that by L-NAME, the inhibitory effects of resveratrol and L-NAME on endothelial tubule formation were nearly equivalent. Lin et al. ${ }^{11)}$ reported that resveratrol inhibits VEGF-induced src activation and the subsequent phosphorylation of vascular endothelial-cadherin, leading to the disruption of tubular network formation of human umbilical vein endothelial cells. These findings suggest that the in vitro antiangiogenic activity of resveratrol involves multiple mechanisms.

Resveratrol had no direct effect on bFGF-induced tubule formation of endothelial cells. Bråkenhielm et al. ${ }^{5)}$ reported that resveratrol prevents both VEGF- and FGF-2 (bFGF)induced angiogenesis in a mouse corneal micropocket model. Similarly, Mousa et $a l^{7)}$ reported that resveratrol exerts the inhibition of FGF-2 (bFGF)-induced neovascularization in a chick chorioallantoic membrane model. VEGF targets endothelial cells exclusively, whereas bFGF acts on a variety of cell types. These results suggest that resveratrol may inhibit the function of non-endothelial cells supporting angiogenesis. It was reported that bFGF induces the expression of COX-2 in fibroblasts of the neovasculatures, and COX-2derived $\mathrm{PGE}_{2}$ is required for $\mathrm{bFGF}$-induced in vivo angiogenesis. ${ }^{19-21)}$ Furthermore, Majima et al. ${ }^{29)}$ reported that COX2-derived $\mathrm{PGE}_{2}$ mediates VEGF expression in fibroblasts in bFGF-induced in vivo angiogenesis. Our study also indicates that bFGF induces COX-2 expression without affecting COX-1 level, resulting in the increased $\mathrm{PGE}_{2}$ production in fibroblasts. In addition, we found that resveratrol prevents bFGF-induced COX-2 expression, resulting in decrease in $\mathrm{PGE}_{2}$ production in fibroblasts. Resveratrol only at $10 \mu \mathrm{M}$ significantly reduced the basal $\mathrm{PGE}_{2}$ production which is generated by COX-1. Jang et al. ${ }^{3)}$ reported that resveratrol serves as a moderate inhibitor for COX. Taken together, it is suggested that the impairment of both COX-2 induction and $\mathrm{PGE}_{2}$ production in fibroblasts might contribute to resveratrol inhibition of bFGF-induced in vivo angiogenesis.

The present study indicates that resveratrol prevents tubular network formation of cultured endothelial F-2 cells in response to VEGF but not to bFGF. The inhibition of NO production might be involved in the mechanisms responsible for the direct antiangiogenic activity of resveratrol on VEGFstimulated endothelial cells. In contrast, resveratrol abrogates COX-2 expression and $\mathrm{PGE}_{2}$ production in bFGF-stimulated fibroblasts, which might lead to the inhibition of bFGFinduced in vivo angiogenesis. We conclude that resveratrol exerts the inhibitory effects on VEGF- and bFGF-induced angiogenesis through different mechanisms including inhibition of NO production in VEGF-stimulated endothelial cells and inhibition of COX-2 induction in bFGF-stimulated fibroblasts. Our findings are helpful in understanding the molecular basis of the beneficial effect of resveratrol on tumor suppression.

Acknowledgments We thank Dr. Akinori Sugiyama (School of Pharmaceutical Sciences, Iwate Medical University), Naohiko Inoue, Tomoyo Ikesako, Shou Hasegawa and Manami Hanada (Kyushu Universisty of Health and Welfare) for their assistance.

\section{REFERENCES}

1) Stoclet J.-C., Chataigneau T., Ndiaye M., Oak M.-H., Bedoui J. E., Chataigneau M., Schini-Kerth V. B., Eur. J. Pharmacol., 500, 299313 (2004).

2) Penumathsa S. V., Maulik N., Can. J. Physiol. Pharmacol., 87, 275286 (2009).

3) Jang M., Cai L., Udeani G. O., Slowing K. V., Thomas C. F., Beecher C. W., Fong H. H., Farnsworth N. R., Kinghorn A. D., Mehta R. G., 
Moon R. C., Pezzuto J. M., Science, 275, 218-220 (1997).

4) Kimura Y., Okuda H., J. Nutr., 131, 1844-1849 (2001).

5) Bråkenhielm E., Cao R., Cao Y., FASEB J., 15, 1798-1800 (2001)

6) Tseng S.-H., Lin S.-M., Chen J.-C., Su Y.-H., Huang H.-Y., Chen C.K., Lin P.-Y., Chen Y., Clin. Cancer Res., 10, 2190-2202 (2004).

7) Mousa Shaymaa S., Mousa Shaaban S., Mousa S. A., Nutr. Cancer, 52, 59-65 (2005).

8) Garvin S., Ollinger K., Dabrosin C., Cancer Lett., 231, 113-122 (2006).

9) Whitsett T., Carpenter M., Lamartiniere C. A., J. Carcinog., 5, 15 (2006).

10) Orallo F., Curr. Med. Chem., 13, 87-98 (2006).

11) Lin M.-T., Yen M.-L., Lin C.-Y., Kuo M.-L., Mol. Pharmacol., 64, 1029-1036 (2003).

12) Folkman J., Nat. Med., 1, 27-31 (1995).

13) Folkman J., Nat. Rev., 6, 273-286 (2007).

14) Dudzinski D. M., Michel T., Cardiovasc. Res., 75, 247-260 (2007).

15) Fukumura D., Gohongi T., Kabambi A., Izumi Y., Ang J., Yun C. O., Buerk D. G., Huang P. L., Jain R. K., Proc. Natl. Acad. Sci. U.S.A., 98, 2604-2609 (2001).

16) Ziche M., Morbidelli L., Choudhuri R., Zhang H.-T., Donnini S., Granger H. J., Bicknell R., J. Clin. Invest., 99, 2625-2634 (1997).

17) Papapetropoulos A., Garcia-Cardeña G., Madri J. A., Sessa W. C., J. Clin. Invest., 100, 3131-3139 (1997).
18) Takahashi S., Uchiyama T., Toda K., Biol. Pharm. Bull., 32, 1840 1843 (2009).

19) Majima M., Isono M., Ikeda Y., Hayashi I., Hatanaka K., Harada Y., Katsumata O., Yamashita S., Katori M., Yamamoto S., Jpn. J. Pharmacol., 75, 105-114 (1997).

20) Masferrer J. L., Koki A., Seibert K., Ann. N. Y. Acad. Sci., 889, 84-86 (1999).

21) Leahy K. M., Ornberg R. L., Wang Y., Zweifel B. S., Koki A. T., Masferrer J. L., Cancer Res., 62, 625-631 (2002).

22) Toda K., Tsujioka K., Maruguchi Y., Ishii K., Miyachi Y., Kuribayashi K., Imamura S., Cancer Res., 50, 5526-5530 (1990).

23) Shankar S., Singh G., Srivastava R. K., Front Biosci., 12, 4839-4854 (2007).

24) Szende B., Tyihak E., Kiraly-Veghely Z., Exp. Mol. Med., 32, 88-92 (2000).

25) Souttou B., Raulais D., Vigny M., J. Cell Physiol., 187, 59-64 (2001).

26) Kubota Y., Kleinmann H., Martin G., Lawley T., J. Cell Biol., 107, 1589-1598 (1998).

27) Wallerath T., Deckert G., Ternes T., Anderson H., Li H., Witte K., Förstermann U., Circulation, 106, 1652-1658 (2002).

28) Scifo C., Cardile V., Russo A., Consoli R., Vancheri C., Capasso F., Vanella A., Renis M., Oncol. Res., 14, 415-426 (2004).

29) Majima M., Hayashi I., Muramatsu M., Katada J., Yamashita S., Katori M., Br. J. Pharmacol., 130, 641-649 (2000). 